\title{
The Difficulty of Measuring the Measurable
}

When we were students of medicine at Zurich University, we were obliged to do a 1-month internship called Häfelipraktikum. For many of us, this job constituted the very first opportunity to become familiar with our future profession, namely with real patients in a hospital. Naturally, this Häfelipraktikum (literally, bedpan practicum) was all but an exciting experience, being precisely the most menial of jobs reserved to us. Nonetheless, we were willing to do a good piece of work, and as a sign of praise, a nurse eventually took us to "measure a patient." It was almost a ceremony to be effected immediately after the patient's admission to the hospital. We were instructed to quantify weight and height and to measure heart rate and blood pressure: single measurements for the physical characteristics and the mean of 3 consecutive measurements for the cardiac parameters.

Now, 30 years later, things have somewhat changed: caregivers have seemingly lost interest in the knowledge of weight and height.1,2 Do you disagree? Just look at some electronic medical records or flow sheets. Can you find a trace of these anthropometric data, and if so, are you sure that they have really been measured? Would you be surprised to know that you are dealing with a copy-paste action from a former medical record, that health care workers simply guessed or estimated, or that the patient or a next of kin actually indicated these numbers?

At this point, it is legitimate to raise some questions. (1) Do we really need these physical characteristics in the ICU setting? (2) If so, how accurate should these findings be? (3) According to the reliability requested, which measurement method is best applied? The first question is readily answered with a clear yes. Numerous everyday procedures are based on the knowledge of weight and/or height, such as prescription of some drugs and nutrition, estimation of creatinine clearance, calculations of body mass index and body surface area, and definition of predicted body weight for protective ventilation in ARDS. ${ }^{3}$

Concerning the second question, most of us probably assume that data in medical records or on flow sheets are

\footnotetext{
The authors have disclosed no conflicts of interest.
}

Correspondence: Andreas Perren MD, Intensive Care Unit, Ospedale Regionale Bellinzona e Valli, CH-6500 Bellinzona, Switzerland. E-mail: andreas.perren@eoc.ch.

DOI: $10.4187 /$ respcare. 03380 reliable. However, this is a mere supposition, and sometimes we should question the data. ${ }^{4}$ Generally speaking, all data measured and used in clinics should be as accurate as possible. The reproducibility of results by different investigators for a given method is probably the most important issue. The article by Dr Bojmehrani and colleagues published in the present issue of RESPIRATORY CARE perfectly fits this context. ${ }^{5}$ They studied the potential impact of differently measured heights on protective ventilation by comparing usual (estimation or tape measurement while patient is supine) and alternative (based on lower leg and forearm dimensions) measuring methods. Height measured in the upright position served as the accepted standard. The authors showed that the methods typically used to obtain a patient's height during mechanical ventilation might not be sufficiently accurate and may lead to inappropriately high tidal volume settings, especially in short patients.

See the Original Study on Page 1025

As the authors did not assess inter-rater variability in their study, we performed an ad hoc experiment in our ICU. Ten nurses consecutively estimated and measured (measuring tape) the height of the same colleague while supine in bed. Height measured in an upright position early in the morning served as the accepted standard. The nurses were asked to perform as usual and without communicating results to the others. Interestingly, SD was higher for measurements than for estimations $( \pm 4.1 \mathrm{vs}$ $\pm 3.6 \mathrm{~cm}$ ), illustrating that measuring might even be more prone to inter-rater variation than visual estimation. One of the main drawbacks of the article by Bojmehrani et al is that the measurement methods used were not sufficiently well described and, by consequence, were probably inconsistently used: the more exact each technique gets, the less margin of interpretation is left to the individual measurer. In this sense, are you surprised that our nurses used three different techniques to measure height, namely, along the ventral part, along the dorsal part, or on the sides of the probationer, respectively? To test the intra-rater variability, we successively instructed 4 nurses to take 3 consecutive height measurements (with a 24-h interval between each of them) of 5 volunteers: the overall SD was $\pm 3 \mathrm{~cm}$. Remarkably, by using the proper technique, each nurse always made the same mistake and either over-reported or 
under-reported the height but with a much smaller intra-rater $\mathrm{SD}$ (approximately $\pm 1.5 \mathrm{~cm}$ ) of the error than the overall. These results, together with the design of the paper by Bojmehrani et al, suggest that the variation in height measurements was due to the sum of two effects: the diverse techniques used by different examiners and the personal or intrarater inaccuracy. A more detailed description of the tape measurement method would probably have given more accurate results, maybe still with a bias but with a reduced variability.

Thus, let's try to answer the third question. The study by Bojmehrani et al, as well as our experiment, highlights the point that improperly defined or inaccurately executed measurement techniques should be abandoned in favor of simpler and somehow self-explaining methods. In this sense, the Chumlea method, which allows height estimation using knee-heel length, might be a valuable alternative. ${ }^{6}$

Accurate measurement is really a difficult task, and the list of possible problems could be easily extended. As a matter of fact, the height of our colleague in an upright position (the accepted standard) was remeasured $12 \mathrm{~h}$ later. At the end of his work day, he was $2 \mathrm{~cm}$ shorter.

\section{Andreas Perren MD Intensive Care Unit Department of Intensive Care Medicine Ente Ospedaliero Cantonale Ospedale San Giovanni Bellinzona, Switzerland}

Paolo Merlani MD

Intensive Care Unit Department of Intensive Care Medicine Ente Ospedaliero Cantonale

Ospedale Civico Lugano, Switzerland

\section{REFERENCES}

1. Tremblay A, Bandi V. Impact of body mass index on outcomes following critical care. Chest 2003;123(4):1202-1207.

2. Geurden B, Wouters C, Franck E, Weyler J, Ysebaert D. Does documentation in nursing records of nutritional screening on admission to hospital reflect the use of evidence-based practice guidelines for malnutrition? Int J Nurs Knowl 2014;25(1):43-48.

3. The Acute Respiratory Distress Syndrome Network. Ventilation with lower tidal volumes as compared with traditional tidal volumes for acute lung injury and the acute respiratory distress syndrome. N Eng1 J Med 2000;342(18):1301-1308.

4. Perren A, Markmann M, Merlani G, Marone C, Merlani P. The fluid balance in critically ill patients. Should we really rely on it? Minerva Anestesiol 2011;77(8):802-811.

5. Bojmehrani A, Bergeron-Duchesne M, Bouchard C, Simard S, Bouchard PA, Vanderschuren A, L'Her E, Lellouche F. Comparison of usual and alternative methods to measure height in mechanically ventilated patients: potential impact on protective ventilation. Respir Care 2014;59(7):1025-1033.

6. Chumlea WC, Roche AF, Steinbaugh ML. Estimating stature from knee height for persons 60 to 90 years of age. J Am Geriatr Soc 1985;33(2):116-120. 